\title{
¿Cómo transitar en el aula para adquirir la competencia traductora? Del aprendizaje por tareas al aprendizaje basado en proyectos ${ }^{1}$
}

\author{
Jimena Weinberg Alarcón \\ jweinberg@uct.cl \\ Universidad Católica de Temuco, Temuco, Chile \\ Lissette Mondaca Becerra \\ Imondaca@educa.uct.cl \\ Universidad Católica de Temuco, Temuco, Chile
}

\begin{abstract}
Resumen
La formación de traductores, en algunos contextos latinoamericanos y en la mayoría de los contextos europeos, se ha fundamentado tradicionalmente sobre la base de competencias, lo que ha permitido que el aprendizaje tanto teórico como práctico satisfaga las demandas de los entornos ocupacionales. Si las competencias son parte de la formación de traductores, ¿por qué resulta tan difícil que los estudiantes logren integrar el aprendizaje de diversas áreas y materias al momento de enfrentar un proyecto real de traducción? Parte de la explicación a este problema radica en que, en el contexto nacional chileno, los programas de formación de pregrado actuales no exigen un estándar mínimo de competencia en la segunda lengua de trabajo, lo que genera un distanciamiento importante entre la teoría y la práctica, al no poder traducir desde el primer año de estudios. Esto, a su vez, da lugar a una disociación en la presentación de contenidos. En respuesta a lo planteado, se revisaron dos metodologías de trabajo en el aula: el enfoque por tareas y el aprendizaje basado en proyectos, con el fin de evaluar su pertinencia para la integración de los componentes de la competencia traductora. Finalmente, se presenta una propuesta didáctica para transitar en el aula desde el aprendizaje por tareas al aprendizaje basado en proyectos.
\end{abstract}

Palabras clave: didáctica de la traducción, enfoque por tareas, aprendizaje basado en proyectos, proceso traductor, competencia traductora.

1 Este artículo se desprende del proyecto de Innovación Docente (PID) “Tutorías académicas disciplinarias: una innovación en la enseñanza de la teoría de la traducción”, 2015-2017, apoyado por la Dirección General de Docencia, Vicerrectoría Académica, Universidad Católica de Temuco, Chile. 


\section{How to Perform in the Classroom to Convey Translating Competence? From Task-Based Learning to Project-Based Learning}

\section{Abstract}

Translator training has, in some Latin American and most European contexts, traditionally been based on competencies, combining theory and practice to meet the demands of occupational settings. However, if competencies are part of translator training, why is it so difficult for students to integrate what they have learned about different areas and subjects into knowledge they can apply when facing a real translation project? The explanation for this issue partially lies in the fact that in Chile undergraduate translation programs do not currently require a minimum level of second-language proficiency. This results in a wide gap between theory and practice, since it is not possible for students to translate right from the beginning in their first year of study. This, in turn, leads to a dissociated presentation of course contents. In response, two teaching methods — task-based learning and project-based learning- were examined in the classroom in order to assess their applicability to integrating the components of translation competence. Finally, a teaching method that involves moving from task-based learning to project-based learning in the classroom is presented.

Keywords: didactics of translation, task-based approach, project-based learning, translation process, translation competence.

\section{Comment agir à la salle de classe pour acquérir de la compétence traductrice ? De l'apprentissage par tâches à l'apprentissage par projets}

\section{Résumé}

La formation professionnelle des traducteurs, dans certains contextes latino-américains et dans la plupart des contextes européens, s'est fondée sur un modèle de compétences qui a permis à la fois d'enseigner et d'apprendre la théorie et la pratique de la traduction pour répondre aux exigences des environnements professionnels. Alors, nous nous demandons pourquoi les étudiants ne réussissent pas si facilement à faire l'intégration des connaissances déjà acquises sur différents sujets et disciplines quand il faut faire face à un projet de traduction réel. Cette question peut être répondue partiellement aujourd'hui au Chili quand on voit que pour s'inscrire aux programmes universitaires de formation en traduction on n'a pas besoin de montrer que l'on est en possession d'un niveau de maîtrise, même minimum, de la deuxième langue de travail. Ceci provoque un décalage important entre la théorie et la pratique pendant la période de formation car l'étudiant n'est pas capable de bien traduire à partir de sa première année d'études. Ceci entraine une présentation dissociée des contenus théoriques et pratiques aux étudiants. Afin d'évaluer sa pertinence dans l'intégration des composantes de la compétence en traduction, deux méthodes de travail dans la salle de classe —l'approche par tâches et l'apprentissage par projets — ont été analysée. Enfin, une proposition didactique est présentée pour passer de l'apprentissage par tâches à l'apprentissage par projets.

Mots-clés : didactique de la traduction, apprentissage par tâches, apprentissage par projets, processus de la traduction, compétence en traduction. 


\section{Introducción}

La enseñanza tradicional ha sido definida como un enfoque que propicia la descontextualización, el aprendizaje memorístico y la desvinculación entre teoría y práctica. Este modelo de enseñanza forma profesionales que no satisfarían las demandas del contexto en el que se desempeñarán (contextos ocupacionales), debido a que desarrollan un perfil que enfatiza los saberes conceptuales, en detrimento de lo práctico. Con el fin de revertir los problemas que se desprenden del enfoque de enseñanza tradicional, la educación adoptó la formación por competencias como nuevo paradigma. Tradicionalmente, la formación de traductores se ha fundado sobre la base de competencias, las que, tal como afirma Kiraly (2000), están bastante bien definidas y consensuadas. Esta formación ha permitido revertir la idea de descontextualización, al posibilitar que el aprendizaje tanto teórico como práctico satisfaga la demanda laboral; ha permitido que el estudiante tenga un rol activo durante su proceso de aprendizaje; y ha desviado la atención del producto para hacer énfasis en el desarrollo del proceso de aprendizaje.

En lo que respecta a la enseñanza de traducción en pregrado en el contexto nacional chileno, el escenario es un tanto particular. Si bien la mayoría de los programas de formación de pregrado se encuentran trabajando bajo un modelo por competencias, lo singular de estos es su vinculación con carreras afines en cuanto utilizan una segunda lengua - a saber, pedagogía en inglés e interpretación, principalmente- $\mathrm{y}$, además, la no exigencia de un estándar mínimo de manejo en la segunda lengua de trabajo. Estas particularidades explican el distanciamiento importante que se genera entre la teoría y la práctica, al no poder traducir desde el primer año de estudios, situación que no depende de la enseñanza tradicional o por competencias, sino que obedece más bien a políticas educativas que buscan mayor inclusión. En esa orientación estriba la dificultad que tienen los estudiantes para adquirir la competencia traductora.

En este contexto, la experiencia de aula que presentamos más adelante da cuenta de una actividad didáctica elaborada bajo la metodología del enfoque por tareas (EPT) y una propuesta para transitar de esta metodología al aprendizaje basado en proyectos (ABP), con el fin de que el estudiante integre las subcompetencias que supone la competencia traductora. Para efectos de este trabajo, revisaremos los conceptos de enfoque por tareas, aprendizaje basado en proyectos, proceso traductor y competencia traductora; presentaremos la propuesta didáctica e indicaremos algunos aspectos a considerar en el tránsito entre estas dos metodologías en el aula.

\section{La enseñanza de la traducción: enfoque por tareas y aprendizaje basado en proyectos}

La metodología conocida como EPT busca que los estudiantes sean agentes sociales en su propio aprendizaje, pues parte del supuesto de que estos aprenden haciendo y, si hacen lo que les interesa o necesitan, hay una contribución a su proceso de aprendizaje y, por ende, a su progreso (Fernández, 2010, p. 5). Por su parte, Sevilla, Sevilla y Callejas (2003) establecen que "el enfoque por tareas es un marco metodológico y, al mismo tiempo, una forma de diseñar el currículo porque integra todos los elementos del proceso educativo: alumnos, profesores, objetivos, contenidos, actividades, materiales, evaluación y las relaciones entre esos elementos" (p. 115). De este modo, el ЕPT es una metodología de trabajo completa que permite una formación integral. Si bien este enfoque tiene su base en la enseñanza de lenguas extranjeras, también es posible aplicarlo 
en otros contextos de enseñanza, como en la formación de traductores.

Una tarea se entiende, en términos generales, como una actividad que se realiza en un tiempo determinado (Fernández, 2010). En la formación de traductores, desde la perspectiva de Hurtado (1999), la tarea podría definirse como "una unidad de trabajo en el aula, representativa de la práctica traductora, que se dirige intencionalmente al aprendizaje de la traducción y que está diseñada con un objetivo concreto, una estructura y una secuencia de trabajo" (p.49). Para Galán (2007), el EPT en la enseñanza de la traducción "consiste en el desarrollo de un producto por parte del alumno, en la mayoría de casos en cooperación" (p. 31), es decir, los estudiantes trabajan en equipo para lograr las tareas que se les encomiendan. Según Fernández (2010, p. 8), las tareas deben ser reales o creíbles, de interés para los alumnos y realizables en un tiempo determinado por el grupo. Además, una misma tarea se puede adaptar a diferentes niveles si se adecúa su complejidad y los recursos que requiere. Marco (2004) también da cuenta de que el EPT se desarrolla en una situación comunicativa simulada que se configura sobre la base de una situación comunicativa real en la lengua de trabajo. Según el autor, con esta metodología "se trataría de pautar tareas en el aula de traducción que condujeran, por etapas y de manera progresiva, a la consecución del objetivo específico propuesto" (Marco, 2004, p. 82).

El enfoque de aprendizaje basado en tareas $(\mathrm{ABT})$, otra denominación para el enfoque por tareas, ha sido constantemente comparado, e incluso confundido, con el enfoque de aprendizaje basado en proyectos. Por ahora, baste señalar que, a pesar de que este último enfoque se organiza de la misma forma que el EPT, la diferencia recae en que en el ABP el "alumno tiene que desarrollar productos más complejos y generalmente reales, por lo cual se adecúa mejor a los niveles avanzados" (Galán, 2007, p. 31). Así, para los primeros niveles de formación de traductores, consideramos que el EPT resultaría más apropiado en tanto conlleva un monitoreo más de cerca del trabajo del estudiante, el que corresponde a tareas bien delimitadas.

En relación con el ABP, Galeana (2006) señala que este puede ser abordado desde tres perspectivas: como un método de instrucción, como una estrategia de aprendizaje y como una estrategia de trabajo. En este artículo nos centraremos en el ABP como una estrategia de aprendizaje en el aula de traducción. Thomas (2000) define el ABP como una serie de actividades complejas desarrolladas en un contexto real en las que el estudiante debe resolver problemas, tomar decisiones e investigar, para lo que debe construir, comprender y aplicar los conocimientos y habilidades adquiridos durante su formación:

Project-based learning (PBL) is a model that organizes learning around projects. According to the definitions found in PBL handbooks for teachers, projects are complex tasks, based on challenging questions or problems, that involve students in design, problem-solving, decision making, or investigative activities; give students the opportunity to work relatively autonomously over extended periods of time; and culminate in realistic products or presentations. (Thomas, 2000, p. 1)

Esta metodología de aprendizaje involucra a los estudiantes en proyectos complejos que simulan una situación de trabajo real relacionada con su área de especialidad. Como metodología de aprendizaje, sigue siendo una situación simulada en cuanto forma parte de una dinámica de aula. Sin embargo, es real dado que el encargo de traducción proviene 
de una necesidad genuina de un cliente de contar con un texto traducido. Esta necesidad moviliza todos los recursos con los que cuenta el estudiante para cumplir con el trabajo; en cierta forma, le obliga a desarrollar y aplicar habilidades y conocimientos y, junto con esto, nuevas herramientas que le serán de utilidad para completar su proyecto. Valero y Navarro (2008) señalan que esta metodología contribuye a desarrollar ciertas competencias blandas, como el trabajo en equipo y el aprendizaje autónomo, este último porque el aprendizaje resultante es producto del esfuerzo de los alumnos en la realización del proyecto.

En el plano de la traducción, la aplicación de esta metodología no varía respecto de otras áreas. Lobato (2013) postula que la metodología del ABP permite que el profesor asuma solo un rol de facilitador en el proceso de enseñanza y que sean los estudiantes quienes participen como agentes activos en el proceso de aprendizaje, lo que permite que estos últimos obtengan mejores resultados en sus traducciones. Al igual que Valero y Navarro, Lobato comparte que esta metodología requiere que los estudiantes adquieran un compromiso con su equipo de trabajo, lo que fomenta la responsabilidad tanto individual como grupal. En términos de Marco (2004) "[...] el instructor [el profesor de traducción] no es el depositario de la autoridad y del conocimiento en el aula, sino que se convierte más bien en un facilitador de la construcción de conocimiento por parte del aprendiz" (p. 83).

En términos generales, las grandes diferencias entre ambas metodologías de enseñanza (grandes en cuanto son significativas para el aprendiz de traducción) se relacionan con la veracidad del encargo de traducción, la complejidad del mismo y el rol en el aula tanto del estudiante como del docente. A estas diferencias se les suma lo que indica Kiraly (2000) respecto del proceso que se lleva a cabo para enfrentar el proyecto de traducción, el que bajo esta metodología implicaría que las tareas intermedias se definan en función de las necesidades que tengan los estudiantes durante el proceso de traslación; por lo tanto, el docente no prevé, no anticipa, no simula ninguna dificultad posible que acarree el encargo de traducción, por lo que no define los pasos a seguir para lograr el objetivo final.

\section{El proceso traductor: etapas observables}

Al referirse al proceso traductor hay dos grandes áreas que diferenciar; una dice relación con lo que ocurre en la mente del traductor durante su proceso de traducción, con el procesamiento de la información a nivel cognitivo y, la otra — de la que nos ocuparemos en la actividad que presentaremos más adelanteda cuenta de los procedimientos traductivos concretos que determinan los pasos o etapas que conlleva la traducción de un texto. En esta actividad se presentan las principales etapas observables de este proceso.

García Yebra (1982), refiriéndose al proceso de la traducción, reconoce dos etapas: la de decodificación o comprensión del texto origen (то) (fase semasiológica) y la de recodificación o de expresión del mensaje y contenido en la lengua meta (LM) (fase onomasiológica). Gile (1995) también reconoce una fase de comprensión, en la que el traductor crea hipótesis respecto de los significados, las que va confirmando y rechazando hasta encontrar el significado correcto de las distintas unidades léxicas; y una fase de reformulación del texto fuente en texto meta (TM), en la que, a partir de nuevas hipótesis, ahora respecto de los equivalentes, se construye el TM. Por su parte, Shreve y Koby (1997) si bien reconocen como los principales procedimientos involucrados en la 
traducción a la comprensión y a la interpretación del mensaje en la lengua y cultura de origen, la transposición del mensaje expresado en la lengua y cultura origen a la lengua y cultura meta, y la expresión del mensaje transpuesto en la lengua y cultura meta, estas se describen a partir de las operaciones cognitivas involucradas en el proceso de la traducción. Lobato (2013) define el proceso de traducción como "las distintas etapas por las que el traductor ha de pasar a la hora de enfrentarse a un texto para llegar a realizar una traducción de calidad" (p. 7) y divide este proceso en tres etapas, a saber, trabajo de pretraducción, trabajo de traducción y trabajo de postraducción. E1 trabajo de pretraducción comprende el contacto con el cliente, la valorización del encargo y el acuerdo de prestación de servicios. Por su parte, el trabajo de traducción contempla la primera lectura del To, la identificación de problemas de traducción, la documentación, la resolución de problemas mediante la aplicación de distintas técnicas de traducción y la transferencia o redacción del TM. Por último, en el trabajo de postraducción se incluye la revisión, la entrega y el cobro.

Para efectos de este trabajo, el proceso de traducción, al igual que el descrito por Lobato (2013), contempla tres etapas. No obstante, estas etapas difieren en las tareas involucradas en cada una de estas. La primera gran etapa de la actividad diseñada es la pretraducción, es decir, el trabajo que efectúan los estudiantes antes de abocarse a la traducción del texto encomendado. En esta etapa se incluyen, en el siguiente orden, el contacto con el cliente, una primera lectura del To para conocer el tema, la organización del trabajo en función del encargo de traducción, la activación de conocimientos previos y la emisión de la orden de trabajo.

La segunda etapa da cuenta de los procesos llevados a cabo por los estudiantes durante la transferencia del sentido del Tо al TM, para lo que requieren de una segunda lectura con el fin de encontrar los posibles problemas de traducción, la identificación de las características del género textual, la documentación y la búsqueda terminológica para encontrar el sentido y los equivalentes en la lengua de llegada, y la traducción propiamente tal.

La tercera y última etapa es la postraducción, en la que los estudiantes evalúan el trabajo realizado, analizando posibles errores de interpretación, estilo, formato y adecuación al género textual y al encargo de traducción. Esta última etapa, dado que la actividad tiene fines educativos, y estamos trabajando con aprendices de traducción, contempla tareas de evaluación, a cargo de los estudiantes (autoevaluación), los compañeros de aula (evaluación de pares) y, en el caso de un proyecto de traducción, del cliente (en caso de tratarse de un encargo real).

\section{La competencia traductora: propuesta de Kelly}

Al realizar una revisión de los distintos autores que exponen los aspectos relevantes de la formación del traductor, nos encontramos con distintas denominaciones, a saber, habilidades, componentes, conocimientos y competencias (Beeby, 1996; Bell, 1991; Delisle, 1980; Gile, 1995; Hurtado, 1996; Hansen, 1997; Hatim y Mason, 1997; Kelly, 2002; Kiraly, 1995; Lowe, 1987; Neubert, 2000; Nord, 1991, 1992; РACTE, 2000; РАСте, 2003; Presas, 1996; Pym, 1992; Risku, 1998; Wilss, 1976). Si bien existen diferencias conceptuales entre estas designaciones, en las que no vamos a profundizar, la gran mayoría utiliza el término 'competencia' para referirse a estas características.

El programa vigente de formación de traductores de la Universidad Católica de Temuco 
(UCT), en Chile, se alinea con el modelo educativo basado en competencias para todas las carreras de pregrado de la universidad. En él se declara como primer eje una formación profesional y académica basada en competencias genéricas y específicas, que incluyen las relativas al saber, el saber hacer y el saber ser y convivir. En este contexto, la institución define un conjunto de diez competencias genéricas, entre las que se encuentran tres identitarias, que todas las carreras deben trabajar hasta su nivel más alto de dominio. Respecto de las competencias específicas, en el caso de la carrera de Traducción Inglés-Español de la UCT, estas nacen de un trabajo de revisión documental, por una parte, y de consulta al medio, por otra.

Entre los modelos de competencias revisados se encuentran el del grupo PACTE $(2000,2003)$ y el de Kelly (2002). Para efectos de este trabajo presentaremos este último modelo, dado que corresponde a una propuesta con fines de diseño curricular y está en la base de la definición de competencias específicas de nuestro plan de estudios, $y$, además, presenta la subcompetencia extralingüística de PACTE de forma desagregada - en las competencias temática y cultural- Esto facilita la práctica docente en cuanto ayuda en la formulación de resultados de aprendizaje más específicos y más focalizados.

El modelo por competencias de Kelly (2002) define la competencia traductora como "la macrocompetencia que constituye el conjunto de capacidades, destrezas, conocimientos e incluso actitudes que reúnen los traductores profesionales y que intervienen en la traducción como actividad experta" (pp. 14-15). De este modo, esta macrocompetencia se desglosa en las subcompetencias que se presentan a continuación en forma piramidal, donde la competencia estratégica - competencia de transfe- rencia para otros (Beeby, 1996; Hansen, 1997; Hurtado 1996; PACTE, 2000)_- ocupa un lugar particular, en la medida en que articula las otras subcompetencias frente a un encargo de traducción:

- Subcompetencia comunicativa y textual en al menos dos lenguas y culturas (comprende fases pasivas y activas de la comunicación, así como las convenciones textuales de las diferentes culturas de trabajo).

- Subcompetencia cultural (comprende no sólo conocimientos enciclopédicos con respecto a los países donde se hablan las lenguas correspondientes, sino también sobre los valores, mitos, percepciones, creencias y comportamientos y sus representaciones textuales). ${ }^{2}$

- Subcompetencia temática (comprende los conocimientos básicos sobre los campos temáticos en los que trabaja el traductor, los cuales le permiten el acceso a la comprensión del texto de origen o de la documentación adicional que emplee).

- Subcompetencia instrumental profesional (comprende el uso de fuentes documentales de todo tipo, la búsqueda de terminología y la gestión de glosarios, bases de datos, etc., el manejo de las aplicaciones informáticas más útiles para el ejercicio de la profesión (tratamiento de textos, autoedición, bases de datos, Internet, correo electrónico), además de otras herramientas, tales como el fax, el dictáfono, etc. Comprende asimismo conocimientos

2 En A Handbook for Translator Trainers (Kelly, 2005), se hace referencia ocasionalmente a la competencia cultural con la denominación de competencia cultural e intercultural; sin embargo, no se profundiza en este concepto. 
básicos para la gestión del ejercicio profesional (contratos, obligaciones fiscales, presupuestos y facturación, etc.), así como la deontología y el asociacionismo profesional).

- Subcompetencia psicofisiológica (comprende el "autoconcepto" o la conciencia de ser traductor/a, la confianza en sí mismo, la capacidad de atención, de memoria, etc.).

- Subcompetencia interpersonal (se trata de la capacidad para interrelacionarse y trabajar profesionalmente en equipo, no sólo con otros traductores y profesionales del ramo (revisores, documentalistas, terminólogos), sino también con los clientes, iniciadores, autores, usuarios, así como con expertos en las materias objeto de traducción).

En su conjunto, todas estas subcompetencias son necesarias para enfrentar un encargo de traducción. Por lo tanto, se identificarán en cada una de las tareas contempladas en la actividad didáctica que presentaremos en el siguiente apartado.

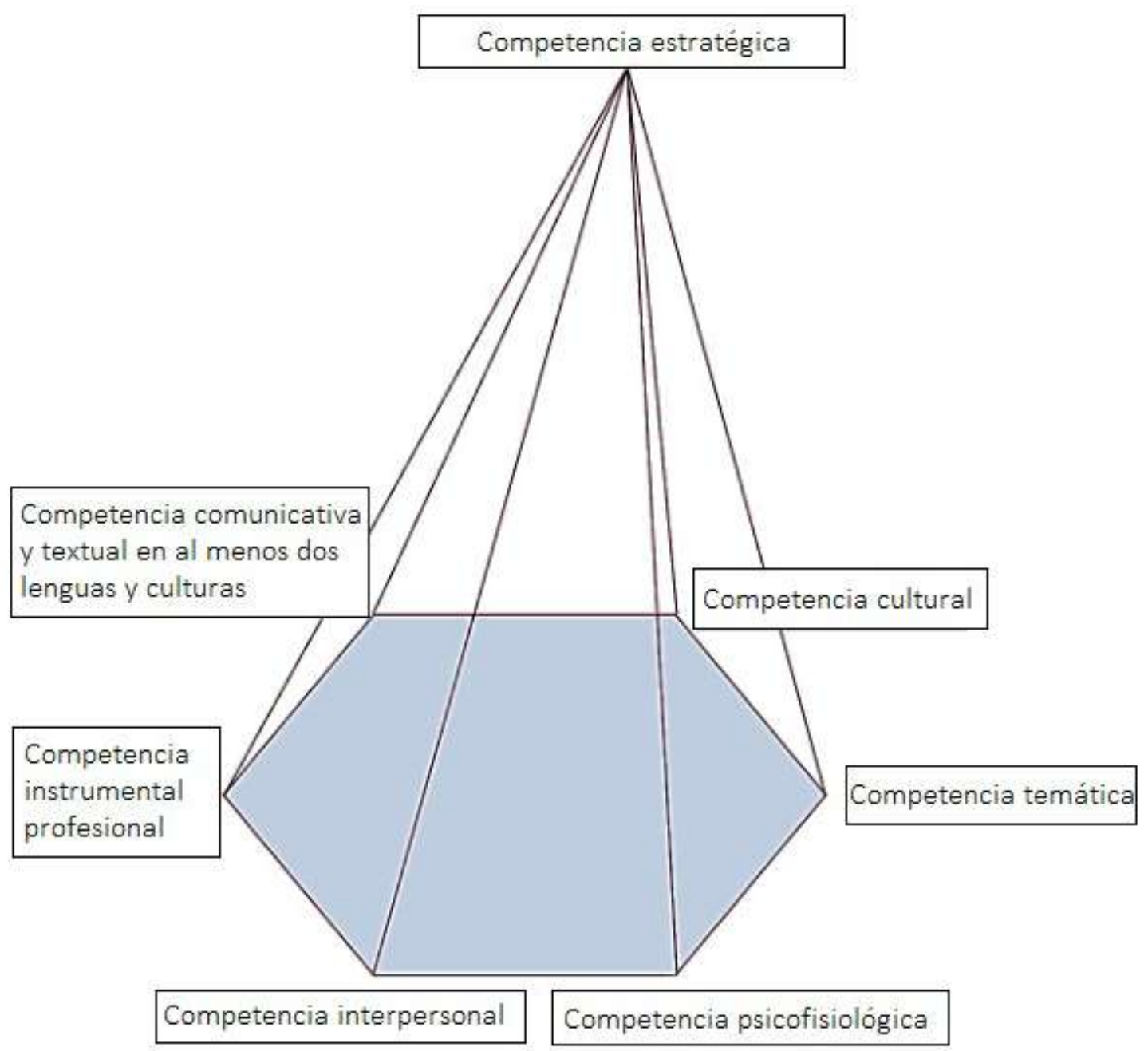

Figura 1. Propuesta de modelo de competencia traductora según Kelly $(2002,2005)$. 


\section{El enfoque por tareas: propuesta de actividad didáctica}

En la actividad didáctica que ejemplificaremos a continuación, diseñada sobre la base del EPT, los estudiantes realizan una serie de tareas que abarcan todo el proceso de traducción, desde aspectos de gestión hasta la traducción del texto y su posterior evaluación. En este sentido, la metodología del EPT resulta de gran utilidad, pues en este enfoque los estudiantes refuerzan y desarrollan las competencias que debe tener un traductor, como lo señala Galán (2007):

la gran aceptación del enfoque por tareas y del aprendizaje basado en proyectos en sus diferentes campos de aplicación se debe a los propios principios en que se asientan dichos enfoques, entendiendo que para el aprendizaje es más importante el proceso que el producto. (p. 33)

En una actividad de este tipo, compuesta por tres macroetapas subdivididas en diferentes tareas, todas las etapas no necesariamente deben tener el mismo peso. La diferencia se puede manifestar en el número de tareas, así como también en el porcentaje que ocupa cada una de estas en la evaluación. En este caso, el objetivo de la actividad es que los estudiantes sean conscientes de la complejidad del proceso traductor, de las etapas que este proceso contempla y que logren visualizar qué subcompetencias de la competencia traductora están desarrollando con cada tarea. Junto con esto, y dado que se trata de una actividad de clase, esta propuesta se acompaña de un marco teórico que da cuenta del tema que se quiere relevar dependiendo de los resultados de aprendizaje de la asignatura y, por lo mismo, contempla en la etapa de postraducción, la fundamentación de los procedimientos utilizados durante el proceso de traducción y la valoración de los aciertos presentes en el producto final. Aunque las tareas busquen relevar alguna de las etapas dentro de este complejo proceso, siempre giran en torno a la traducción de un texto. A este respecto, Sevilla et al. (2003), señalan que:

si se trata de formar traductores profesionales, las unidades didácticas deben girar en torno a la traducción de textos, con el fin de simular en el aula el ejercicio profesional, de modo que la selección de material para traducir aparece como un aspecto fundamental en la didáctica de la traducción científico-técnica. (p. 113)

La actividad que se presenta a continuación está orientada a estudiantes de traducción del área técnico-científica de la Universidad Católica de Temuco; sin embargo, es factible aplicarla en la traducción de otras áreas. E1 material didáctico está diseñado sobre la base del artículo de divulgación científica Mineral Prospecting and Exploration, publicado por la empresa Atlas Copco (2007); el trabajo está planificado para su desarrollo en equipos de cuatro estudiantes. En cada tarea se explicita su objetivo, la instrucción para que el docente la aplique y las subcompetencias que se espera que el estudiante desarrolle. Las tareas formuladas se presentan en el orden que consideramos lógico dentro del proceso traductor; sin embargo, pueden combinarse para dar cumplimiento al objetivo de aprendizaje planteado para la clase.

\subsection{Pretraducción}

Las siguientes tareas han sido diseñadas para ser aplicadas en la etapa de pretraducción del texto. Proponemos iniciar siempre esta etapa con un marco teórico que responda al resultado de aprendizaje de la unidad de la asignatura y que sitúe las tareas que se presentarán a continuación. Con este trabajo el estudiante contribuye al desarrollo de la subcompetencia temática, pues le permite reforzar contenidos teóricos relacionados con la práctica de la traducción. 


\section{Tarea 1. Contacto con el cliente}

Objetivo de la tarea: tratar de forma profesional con el cliente como participante del encargo de traducción.

Instrucción: el docente simula un contacto con un cliente ${ }^{3}$ ficticio, pero que bien podría ser real; por ejemplo, una secretaria, a través de un correo electrónico. La secretaria solicita la traducción del texto para unos receptores, que serán académicos del programa de ingeniería en minas para el que trabaja la secretaria. El docente solicita a los estudiantes que, como traductores profesionales, respondan a la solicitud y consideren todos aquellos aspectos que crean relevantes al momento de iniciar el contacto con el cliente. Una vez que los estudiantes han respondido el correo electrónico, el docente solicita que cada grupo comparta su respuesta con la clase y mencione qué aspectos consideró importantes al momento del contactarse por primera vez con quien será su cliente.

Subcompetencias: estratégica e interpersonal, dado que se busca que los estudiantes adquieran la capacidad de, primero, relacionarse entre ellos como grupo de trabajo para concertar la manera como abordarán el contacto con el cliente y, segundo, relacionarse con el cliente, quien será su contacto permanente hasta la finalización del trabajo.

\section{Tarea 2. Conocimientos previos}

Objetivo de la tarea: activar conocimientos previos acerca del tema del texto por traducir a través de preguntas abiertas, lluvia de ideas,

3 Se entenderá por cliente la persona que realiza el contacto y efectúa el encargo de traducción, mientras que se denominará receptor a quien, al finalizar el proceso traductor, es el usuario de la traducción. elaboración de mapas conceptuales y planteamiento de hipótesis.

Instrucción: el docente busca activar cualquier conocimiento que tengan los estudiantes acerca del tema sobre el cual trata el texto de trabajo. En relación con los conocimientos previos, Miras (2002) establece que siempre existe un conocimiento anterior y que ninguna persona inicia un aprendizaje de cero; sin embargo, en caso de que no exista tal conocimiento en los estudiantes, "el docente debe desarrollar actividades que permitan alcanzarlos mediante actividades individuales y grupales" (Escami1la, 1999, p. 78). Así, el docente puede solicitar a los grupos de trabajo que desarrollen una o más de las subtareas que se presentan a continuación:

- Preguntas abiertas a toda la clase: el docente pide a los estudiantes que respondan las siguientes preguntas: ¿Conocen acerca de qué trata la actividad minera? ¿Qué saben respecto de la explotación minera? ¿Conocen las etapas previas a la explotación? ¿Con qué pueden asociar los conceptos de prospección y exploración?

- Lluvia de ideas sobre el tema: El docente solicita a los grupos de trabajo que comenten lo que saben sobre la temática del texto por traducir. Luego, pide a los grupos que compartan sus ideas con el resto de la clase, da un espacio de discusión para establecer aciertos y errores que puedan haber surgido respecto del tema y, finalmente, reúne las ideas clave que contribuirán al desarrollo de las actividades que siguen.

- Elaboración de mapas conceptuales: el docente pide a los estudiantes que compartan en grupos algunas ideas sobre la temática del texto por traducir. Luego, les ayuda a organizar las ideas en ejes temáticos con el 
fin de que cada grupo tome un eje y lo desarrolle en un mapa conceptual. Finalmente, los grupos exponen sus mapas conceptuales ante la clase.

- Levantamiento de hipótesis: el docente solicita a los grupos que, solamente leyendo el título y los subtítulos del texto, formulen hipótesis acerca de su contenido. Luego, los estudiantes exponen sus respuestas ante la clase y organizan las ideas entre todos para rearmar el texto.

Subcompetencias: temática, debido a que los estudiantes plasman los conocimientos que tienen acerca del campo temático en el que se enmarca la traducción que realizarán; psicofisiológica, ya que los estudiantes deben confiar en sus propias capacidades y conocimientos y en su capacidad de memoria para realizar las tareas; además, se fomenta la confianza, dado que el estudiante descubre que algo sabe acerca del tema y que no empieza de cero; e interpersonal, en la medida en que deben compartir sus ideas con su equipo de trabajo y resolver posibles conflictos para aunar conocimientos y luego compartirlos con la clase.

\section{Tarea 3. Encargo de traducción}

Objetivo de la tarea: Identificar tema y subtemas del texto por traducir y anticipar posibles problemas de traducción.

Instrucción: E1 docente informa a los estudiantes quién será el receptor del TM y cuál es la finalidad de la traducción que realizarán, y les solicita que lean el texto por traducir, el que conocerán en términos de área temática, organización discursiva, presencia de fraseología y terminología del área, extensión, etc., para anticipar posibles problemas y dificultades de traducción que emanen del encargo. Luego, los estudiantes registran los posibles problemas de traducción y explican sus causas, para compartirlas con el resto de la clase. El encargo para esta tarea corresponde al siguiente:

Texto por traducir: Mineral Prospecting and Exploration, de Atlas Copco.

Receptores: académicos de una carrera de ingeniería en minas.

Finalidad de la traducción: dar a leer a los estudiantes de primer año el texto como material de apoyo para el tema que se está trabajando en la clase.

Subcompetencias: comunicativa y textual, debido a que ponen en práctica su conocimiento acerca de la lengua origen (LO); cultural, en cuanto aplican sus conocimientos sobre la cultura en la que se enmarca el то; y temática, al activar los conocimientos que ya poseen sobre el área temática del texto por traducir $\mathrm{y}$, además, adquieren nuevos conocimientos sobre esta.

\section{Tarea 4. Etapas del trabajo}

Objetivo de la tarea: organizar las etapas del trabajo en función del encargo de traducción.

Instrucción: el docente pide a los estudiantes que organicen, en orden lógico, en el cuadro que se presenta a continuación, los pasos que podrían seguir para dar respuesta al encargo de traducción, prestando atención a los elementos indicados en el paréntesis.

Subcompetencias: interpersonal, ya que los miembros de cada grupo trabajan en conjunto para organizar los pasos que seguirán para llevar a cabo el encargo de traducción, y estratégica, pues los estudiantes deben poner en práctica todos los procedimientos que se aplican a la organización del trabajo. 
Tabla 1. Organización de etapas de trabajo

Editar el texto traducido (la edición aplica a la lengua materna)

Organizar el proceso de traducción (una buena organización le permite enfrentar de mejor forma las dificultades de traducción)

Contactarse con el cliente (el cliente no siempre es el receptor del texto)

Organizar el grupo de trabajo (al momento de distribuir los roles, recuerde que no todos tenemos las mismas habilidades)

Preparar un glosario (este recurso terminológico lo acompañará durante todo el proceso traductor)

Contactarse con expertos temáticos (el experto temático es un conocedor del campo temático del que trata la traducción y no necesariamente conoce la lengua extranjera de trabajo)

Identificar terminología (en algunas áreas, la terminología es una palabra del léxico común que adquiere un nuevo significado en un área específica del saber)

Documentarse (además de los textos paralelos existen otros recursos como los videos, diccionarios de imágenes, entre otros, para adquirir conocimiento y terminología acerca de un tema)

Analizar el texto origen (el análisis incluye tanto los factores externos como internos del texto)

Generar la orden de trabajo (el cobro no depende solo del número de palabras que tiene el texto por traducir) Leer el texto (no olvide tener claro el objetivo que orienta su lectura)

Traducir el texto (siempre tener el encargo de traducción a la vista)

\section{Tarea 5. Distribución de tareas}

Objetivo de la tarea: organizar el equipo de trabajo y los recursos requeridos para dar cumplimiento al encargo.

Instrucción: el docente solicita a los estudiantes que completen el siguiente cuadro, con el fin de organizar la traducción del texto: pasos a seguir, tiempo destinado para cada tarea, recurso que requiere, estudiante a cargo y rol que cumple el estudiante. Los roles contemplan: un gestor, un documentalista/terminólogo, un traductor y un revisor/editor.

Dado que lo que se requiere es trabajar en equipo de manera colaborativa, esta tarea se inicia con un análisis de las fortalezas y las debilidades de los estudiantes para distribuir los roles. El docente apoya de cerca esta tarea, ya que, al conocer el desempeño de cada uno de los estudiantes en las distintas actividades de clase, puede proporcionar información que ayude a tomar decisiones.
Subcompetencias: interpersonal, ya que los miembros de cada grupo trabajan en conjunto para determinar cuáles serán los pasos para cumplir con el encargo de traducción, el tiempo que requerirán para ellos, los recursos que demandan, quién se hará cargo de cada paso y el rol que cumplirá cada estudiante en su equipo; y estratégica, pues para realizar esta tarea los estudiantes ponen en práctica todos los procedimientos que se aplican a la organización y realización del trabajo.

\section{Tarea 6. Documentación}

Objetivo de la tarea: seleccionar expertos temáticos y otras fuentes de consulta.

Instrucción: el docente solicita a los equipos de trabajo que completen el primero de los cuadros que se presentan a continuación con el fin de organizar su proceso de documentación e indiquen tres expertos que eventualmente podrán consultar frente a un problema que se genere 
Tabla 2. Distribución de tareas.

\begin{tabular}{l|l|l|l|l|l}
\hline & Etapas de trabajo & Duración por etapa & Recursos requeridos & Estudiante a cargo & Rol \\
\hline 1 & & & & & \\
2 & & & & & \\
3 & & & & & \\
\hline
\end{tabular}

durante el trabajo, declaren el aporte que el experto puede hacer en la solución del problema e indiquen en qué etapa del proceso traductor el experto sería de mayor utilidad. Junto con esto, a través de un ejercicio de role playing, deben simular el contacto con el experto temático; en muchas ocasiones, se solicita a docentes de carreras afines con los temas a traducir que participen de esta instancia con el fin de que el estudiante se socialice con el experto y tenga una práctica de colaboración cuasi real. Luego, el docente pide a los estudiantes que indiquen, en el segundo cuadro, qué otras fuentes de consulta, fuera del contacto con expertos temáticos, les podrían ayudar a adquirir más información acerca del tema antes de traducir y a solucionar posibles problemas de traducción.

Subcompetencias: interpersonal, dado que los miembros del equipo deben aprender a relacionarse con expertos en los campos temáticos de los versa la traducción, e instrumental profesional, ya que los grupos deben seleccionar y evaluar la fiabilidad de diferentes fuentes documentales que les serán útiles para la traducción que llevarán a cabo.

\section{Tarea 7. Insumos para una orden de trabajo}

Objetivo de la tarea: identificar aspectos a considerar en una orden de trabajo/cotización.

Instrucción: al momento de generar una orden de trabajo, son variados los factores que se deben tener en consideración, por ejemplo, ¿el texto presenta mucha terminología? Si el cliente solicita que el trabajo sea realizado con una memoria de traducción, ¿cuento con esta? ¿Conozco algún experto temático que pueda ayudarme a resolver dudas puntuales sobre el texto?, entre otros. E1 docente solicita a los estudiantes que hagan una lista de todos los elementos que deberían considerar al momento de emitir un presupuesto de traducción. Para realizar esta tarea es relevante haber realizado al menos una lectura del texto por traducir; solo así el estudiante será capaz de visualizar la tarea y responder a las consultas planteadas. Luego, los estudiantes comparten sus ideas con el resto de la clase y generan un listado final con los puntos que todos considerarán.

Subcompetencias: se pretende desarrollar la subcompetencia interpersonal, dado que se espera que los estudiantes adquieran la capacidad de, primero, relacionarse entre ellos para acordar qué aspectos son importantes al momento de completar una orden de trabajo y, segundo, relacionarse con el cliente para entregarle toda la información requerida para hacerse cargo del trabajo. Junto con esto, y si después de realizar el análisis planteado en la tarea surge la necesidad de aprender a utilizar alguna aplicación informática, alguna herramienta profesional y adentrarse más en el conocimiento del mercado, también se estará desarrollando la subcompetencia instrumental profesional. 
Tabla 3. Selección de expertos temáticos.

\begin{tabular}{|c|c|c|c|}
\hline & Experto 1 & Experto 2 & Experto 3 \\
\hline \multicolumn{4}{|l|}{ Descripción del experto } \\
\hline \multicolumn{4}{|c|}{$\begin{array}{l}\text { Motivo de selección/ problema que podría solucionar/ Objetivo de la } \\
\text { consulta (comprender un concepto, consultar sobre dónde encontrar } \\
\text { más información acerca del tema, seleccionar un equivalente, revisar } \\
\text { la propuesta de traducción, etc. }\end{array}$} \\
\hline $\begin{array}{l}\text { Ełapa del proceso traductor (pretraducción, traducción o } \\
\text { postraducción). }\end{array}$ & & & \\
\hline
\end{tabular}

Tabla 4. Selección de otras fuentes de consulta.

\begin{tabular}{l|l|l|l}
\hline Tipo de recurso & Nombre & Bibliografía & Propósito \\
\hline Diccionarios & & & \\
\hline Sitios web & & & \\
\hline Glosarios & & & \\
\hline Memorias de traducción & & & \\
\hline
\end{tabular}

\section{Tarea 8. Orden de trabajo}

Objetivo de la tarea: elaborar y completar la orden de trabajo en función de los requerimientos del encargo de traducción.

Instrucción: el docente solicita a los estudiantes que, sobre la base de todos los antecedentes recopilados en las tareas anteriores, revise la propuesta de orden de trabajo, la adecúe a los requerimientos de su encargo y la complete con el fin de entregarla al cliente. En algunas ocasiones, esta cotización debe ser "negocia$\mathrm{da}$ " con el cliente y, una vez llegado a acuerdo, puede el contenido ser modificado.

Subcompetencias: principalmente, la subcompetencia interpersonal, en cuanto se espera que los estudiantes adquieran la capacidad de relacionarse entre ellos, para completar la orden de trabajo, y con el cliente, para enviársela y para recibir su retroalimentación. No obstante, todas las demás subcompetencias están de alguna forma presentes en esta tarea, pues los estudiantes utilizan todo el conocimiento que tienen sobre la práctica traductora para elaborar el presupuesto solicitado.

\subsection{Traducción}

Las tareas que se presentan a continuación han sido diseñadas para ser aplicadas en la etapa de traducción del texto.

\section{Tarea 9. Análisis de texto}

Objetivo de la tarea: analizar los factores externos e internos del texto para lograr una mejor comprensión del texto a traducir.

Instrucción: el docente solicita a los estudiantes que lean, de manera crítica, el texto por traducir y que, sobre la base de la ficha que se presenta a continuación, ${ }^{4}$ realicen un análisis de los principales factores del To. Luego, los estu-

4 Ficha de análisis textual (Orozco, 2012, p. 106). 
Tabla 5. Orden de trabajo.

\begin{tabular}{lll}
\hline Orden de trabajo & & \\
\hline Fecha de recepción del trabajo & $N^{\circ}$ de orden \\
\hline Traductores & \\
\hline Nombre & Celéfono & Correo \\
\hline Nombre & Teléfono & \\
\hline Cliente & \\
\hline Nombre y/o Razón Social & \\
\hline Rut/DNi & Dirección \\
\hline Teléfono & Correo \\
\hline Servicio & \\
\hline Revisión & \\
\hline Edición & \\
\hline Bases ducción (especificar el tipo) & \\
\hline
\end{tabular}

Bases de datos terminológicas

Otro

Contenido del Trabajo

Texto Meta:

Receptor

Objetivo de la traducción

Texto Original:

Nombre

Autor

Fuente

№ de páginas (aprox. 250 palabras por pág.)

Área temática

Clase de texto (autónomo o parte de una estructura mayor )

Tipo de texto (contenido, función)

Léxico y/o terminología

Fraseología

¿Cómo transitar en el aula para adquirir la competencia traductora? Del aprendizaje por tareas al aprendizaje basado en proyectos 
Elementos no verbales
Información confidencial

Presupuesto

№ aprox. de páginas del texto meta

Costo total aproximado $\$$

Forma de pago (transferencia, cheque, efectivo, etc.)

Formato de entrega (correo electrónico, impreso, CD, etc.)

Dirección de envío

Fecha de entrega

Abono (si el texto es de más de 50 páginas, se debe abonar el

$50 \%$ del costo de la traducción)

Observaciones

diantes comparten el trabajo realizado con la clase. De acuerdo con Weinberg, Caamaño y Mondaca (2018):

...dado que el traductor se debe acercar a la comprensión total del texto, tanto el análisis lingüístico como el extralingüístico son de vital importancia; reparar en la función del texto, los modos de enunciación, los tipos de oraciones, los rasgos prototípicos de un género textual, así como también en todo lo que implica la circunstancia de enunciación, es decir, tiempo, lugar, estatus de los participantes, saber compartido, entre otros, son los elementos del texto que pasan desapercibidos si el propósito de la lectura no es la traducción. (p. 324)

Subcompetencias: comunicativa y textual, dado que a través de la lectura trabajan la capacidad para comprender y analizar textos y también reconocen los rasgos prototípicos del texto por traducir, y cultural, ya que para analizar el texto ponen en práctica todos aquellos conocimientos que se relacionen con la cultura de origen; logran comprender algunas relaciones presentes entre las culturas y sus textos.

\section{Tarea 10. Problemas de traducción}

Objetivo de la tarea: identificar posibles problemas de traducción.

Instrucción: el docente solicita a los estudiantes que lean nuevamente el texto por traducir e identifiquen en total un número de diez posibles problemas de traducción de las siguientes categorías: de comprensión, de transferencia, de reexpresión o pragmáticos. Luego, los estudiantes completan la siguiente tabla, con el fin de prever soluciones para aquellos problemas potenciales. 
Tabla 6. Análisis del texto origen

\begin{tabular}{|c|c|}
\hline Factor & Análisis del Texto Origen \\
\hline \multicolumn{2}{|l|}{$\begin{array}{l}\text { Autor/Emisor (datos biográficos relevantes, traducciones ya realizadas de otras } \\
\text { obras, etc.) }\end{array}$} \\
\hline \multicolumn{2}{|l|}{$\begin{array}{l}\text { Género textual (receta de cocina, prospecto de medicamento, crónica } \\
\text { periodística...) }\end{array}$} \\
\hline \multicolumn{2}{|l|}{$\begin{array}{l}\text { Función/es del texto (informativa, argumentativa, instructiva, estética, } \\
\text { exhortativa...) }\end{array}$} \\
\hline \multicolumn{2}{|l|}{ Mecanismos del autor para lograr la función/es del texto } \\
\hline \multicolumn{2}{|l|}{ Registro (hiperformal, culto, estándar, coloquial, vulgar...) } \\
\hline \multicolumn{2}{|l|}{ Tono (próximo al lector/distante...) } \\
\hline \multicolumn{2}{|l|}{$\begin{array}{l}\text { Público al que va dirigido (edad, categoría socio-cultural y económicas } \\
\text { aproximadas, conocimientos que se le suponen...) }\end{array}$} \\
\hline \multicolumn{2}{|l|}{ Ideas principales (expresadas en pocas frases que sean lo más sintéticas posible) } \\
\hline \multicolumn{2}{|l|}{$\begin{array}{l}\text { Rasgos estilísticos destacables (prosa poética, abundancia de verbos/de } \\
\text { sustantivos/de datos, etc.) }\end{array}$} \\
\hline \multicolumn{2}{|l|}{$\begin{array}{l}\text { Estructura interna del texto (cómo está organizado, si tiene introducción, } \\
\text { conclusión, etc. aunque no esté marcado; qué elementos de nexo utiliza para } \\
\text { hilvanar las ideas, etc.) }\end{array}$} \\
\hline \multicolumn{2}{|l|}{$\begin{array}{l}\text { Nivel de dificultad temático (¿̇has encontrado palabras/expresiones que no } \\
\text { conocías?, ¿̇i tú pertenecieras al tipo de público al que va dirigido el texto } \\
\text { originalmente te ocurriría lo mismo?) }\end{array}$} \\
\hline $\begin{array}{l}\text { Impresión del lector (con qué frase te quedarías, qué destacarías tú personalmente } \\
\text { del texto) }\end{array}$ & \\
\hline
\end{tabular}

Tabla 7. Problemas de traducción.

\begin{tabular}{l|l|l|l}
\hline $\begin{array}{l}\text { Fragmento que presenta el } \\
\text { problema (то) }\end{array}$ & Tipo de problema & Vía de solución & Posible solución propuesta \\
\hline & & & \\
\hline
\end{tabular}

Subcompetencias: comunicativa y textual, ya que los estudiantes deben entender el funcionamiento de la lengua inglesa (sintaxis, formación de palabras, convenciones, etc.) y los rasgos prototípicos de los géneros textuales para poder identificar posibles problemas de traducción que enfrentarán, y estratégica, en cuanto permite a los estudiantes poner en práctica todos aquellos procedimientos que aplican a la identificación y resolución de problemas.

\section{Tarea 11. Género textual}

Objetivo de la tarea: identificar el género textual del texto por traducir a partir del análisis de los distintos niveles del texto. 
Instrucción: el docente solicita a los estudiantes que lean nuevamente el texto a traducir, les pide que observen sus características a nivel de superestructura, macroestructura y microestructura, y luego, respondan las siguientes preguntas:

- ¿A qué género textual pertenece el texto? ¿Por qué?

- ¿Cómo se organiza el texto? ¿De qué partes se compone? ¿Títulos, subtítulos, capítulos, apartados?

- ¿Cómo se estructura el tema? ¿Idea principal, ideas secundarias?

- ¿Qué características tiene ese género textual?

- ¿Qué función es la que predomina en este género? ¿En qué elementos gramaticales se evidencia?

- ¿E1 texto presenta terminología?

Subcompetencias: cultural, comunicativa y textual, pues aplicarán los conocimientos que tengan acerca géneros textuales tanto en LO como en LM para determinar a qué género corresponde el то; deben dar cuenta de las convenciones del género textual con el que están trabajando, evaluar si las convenciones se comparten en ambas lenguas, etc.

\section{Tarea 12. Marcadores textuales y comprensión}

Objetivo de la tarea: identificar los marcadores textuales con el fin de traducirlos adecuadamente.

Instrucción: los marcadores textuales son unidades del discurso de contribuyen a la cohesión del texto. Con el propósito de que los estudiantes entiendan la función de los marcadores textuales y, por ende, los traduzcan adecuadamente, se proponen las siguientes subtareas:

- El docente pide a los estudiantes que identifiquen los marcadores textuales del to y los clasifiquen según su función (oposición, causa, consecuencia, analogía, introducción, conclusión, adición, ejemplificación). ¿Existe algún marcador que genere un problema de traducción? ¿Cómo lo solucionarían?

- El docente solicita a los estudiantes que expliquen las distintas opciones de traducción del marcador textual but y que, posteriormente, traduzcan las oraciones que se presentan a continuación.

- But how do you find these accumulations of metallic minerals in the earth's crust?

- Reverse circulation drilling is a fast, but inaccurate, exploration method, which uses near-standard percussion drilling equipment.

- Every orebody has its own story, but there is often a sequence of findings.

Una vez realizadas estas subtareas, se les solicita que respondan las siguientes preguntas:

¿Han traducido todos los but de la misma manera?

¿Qué conclusiones extraen de este ejercicio?

Subcompetencias: Se busca desarrollar la subcompetencia comunicativa y textual, debido a que los estudiantes deben hacer uso del conocimiento ya adquirido en lengua inglesa para identificar los marcadores textuales que contribuyen a la cohesión del texto. Junto con esta, como debe establecer si alguno de los marcadores constituye un problema de tra- 
ducción, también se está desarrollando la subcompetencia estratégica.

\section{Tarea 13. Documentación y terminología}

Objetivo de la tarea: utilizar videos para adquirir los conocimientos y la terminología necesaria para la comprensión del texto por traducir.

Instrucción: el docente solicita a los equipos de trabajo que revisen los siguientes videos y los comenten al interior de sus grupos y luego con los demás de la clase.

- Etapas de la minería-prospección: https:// www.youtube.com/watch?v=s3frp5iNGo8

- Exploración y minería subterránea: https:// www.youtube.com/watch?v=nn4U7Gz6fIw

Posteriormente, se les pide den respuesta a las siguientes subtareas y que compartan sus respuestas con la clase:

- Explique con sus palabras las fases que contemplan las etapas de prospección y exploración.

- Explique en términos generales lo que deben asegurar las compañías mineras para comenzar la búsqueda de los minerales metálicos.

- Explique si es posible definir en qué punto la prospección da paso a la exploración.

Posteriormente, el docente solicita a cada grupo de trabajo que lea el texto por traducir e identifique en este la terminología propia del área temática. Una vez que han identificado los términos, cada grupo elabora un glosario unificado con equivalentes que más adelante utilizarán en el traslado del texto a la LM.
Finalmente, con el fin de validar el instrumento, el docente solicita a los equipos de trabajo que comenten e intenten explicar los conceptos de mineralization y bedrock, y propongan un equivalente para cada uno. Los estudiantes comparten su explicación y justifican la elección de los equivalentes ante los demás grupos.

Subcompetencias: temática, ya que los estudiantes ponen en práctica el conocimiento que ya tienen sobre área temática del texto por traducir y, al mismo tiempo, adquieren nuevo conocimiento; y la instrumental profesional, al organizar y realizar una búsqueda terminológica para gestionar un recurso terminológico (glosario).

\section{Tarea 14. Redacción en lengua meta}

Objetivo de la tarea: evaluar coherencia y cohesión en textos traducidos sobre el área sin conocer el original.

Instrucción: con el fin mejorar la redacción en lengua española, el docente entrega a cada grupo para traducir un texto breve en inglés, de la misma temática del texto base de la actividad didáctica (prospección y exploración minera). Cada grupo recibe un texto diferente, por lo que desconocen el To con el que están trabajando los demás grupos. Una vez que los estudiantes han finalizado la traducción, el docente retira solo los textos meta y los intercambia (cada equipo recibe una traducción distinta de la que ha realizado). Solo contando con la traducción, cada grupo deberá revisar el texto producido por otro y evaluarlo en términos de coherencia y cohesión, comprensibilidad y lengua española. Finalmente, el docente solicita a cada grupo que retroalimente el trabajo de sus compañeros.

Subcompetencias: psicofisiológica, pues el objetivo es que los estudiantes tengan confianza 
Tabla 8. Procedimientos técnicos de traducción.

\begin{tabular}{l|l|l|l}
\hline Fragmento (то) & Fragmento (тм) & Procedimiento utilizado & Vía de mejora \\
\hline & & & \\
& & & \\
\hline
\end{tabular}

en sus capacidades como futuros traductores para evaluar, de manera crítica, el trabajo realizado por otros; comunicativa y textual, dado que revisan un texto que debe estar correctamente formulado en la LM; y estratégica, en cuanto los estudiantes, haciendo uso de sus conocimientos acerca de todo lo que implica el proceso el traductor, revisan y evalúan los textos traducidos.

\section{Tarea 15. Traducción}

Objetivo de la tarea: traducir el texto Mineral prospecting and exploration conforme al encargo de traducción.

Instrucción: el docente solicita a los estudiantes que, una vez realizadas las tareas previas, procedan a trasladar el Tо a LM, a la luz del encargo de traducción.

Subcompetencias: el traslado del texto de la LO a la LM permite que los estudiantes pongan en práctica todo su conocimiento y utilicen todas las herramientas de las que disponen para realizar la traducción, de modo que esta tarea busca desarrollar todas las subcompetencias que supone la competencia traductora: comunicativa y textual, cultural, temática, instrumental profesional, psicofisiológica, interpersonal y estratégica.

\subsection{Postraducción}

Las siguientes tareas han sido diseñadas para ser aplicadas en la etapa de postraducción del texto.

\section{Tarea 16. Adecuación al encargo}

Objetivo de la tarea: realizar un análisis del TM para autoevaluar el cumplimiento del encargo de traducción.

Instrucción: el docente solicita a cada grupo de trabajo que, utilizando la ficha de análisis textual $^{5}$ de Orozco (2012), analice su traducción con el fin evaluar si da cumplimiento a lo estipulado en el encargo de traducción. Junto con esto, y a partir de los resultados, se les solicita una evaluación cualitativa del trabajo colaborativo realizado.

Subcompetencias: cultural, debido a que para analizar los factores externos e internos del texto, los estudiantes ponen en práctica todos aquellos conocimientos que poseen respecto de la cultura meta; y comunicativa y textual, ya que evalúan el TM sobre la base de sus conocimientos de la lengua española.

5 Ficha de análisis textual utilizada en la tarea 10. 
Tabla 9. Errores y aciertos en la traducción.

\begin{tabular}{l|l|l|l}
\hline Categoría & Fragmento to & Fragmento тм & Fundamentación \\
\hline Falsos sentidos & & & \\
Sinsentidos & & & \\
Aciertos & & & \\
\hline
\end{tabular}

\section{Tarea 17. Procedimientos técnicos}

\section{de traducción}

Objetivo de la tarea: identificar y evaluar el uso de los procedimientos técnicos de traducción en el texto traducido por un par.

Instrucción: el docente pide a los grupos de trabajo que revisen la traducción realizada por otro grupo, con el fin de identificar en el texto traducido los procedimientos de traducción utilizados (modulación, transposición, equivalencia, etc.). Luego, los estudiantes deben completar la Tabla 8 con la información recabada y, en caso de que el procedimiento utilizado no resulte apropiado, deben proponer una alternativa que mejore la traducción. Luego, el grupo revisor entrega las propuestas de mejora al grupo evaluado.

Subcompetencias: se busca desarrollar, además de la subcompetencia comunicativa y textual al requerir el manejo de ambas lenguas de trabajo, la estratégica, pues los estudiantes revisan y evalúan el trabajo realizado por otro grupo, utilizando todos sus conocimientos sobre la práctica traductora; y la interpersonal, pues deben entregar las propuestas de mejora al otro grupo y justificar las decisiones tomadas.

\section{Tarea 18. Errores y aciertos}

Objetivo de la tarea: identificar errores y aciertos en el texto traducido por un par.
Instrucción: el docente pide a los grupos que completen la siguiente tabla con falsos sentidos, sinsentidos y aciertos ${ }^{6}$ que encontraron al revisar la traducción de otro grupo.

- Falsos sentidos: segmentos del texto en que la traducción no tiene el mismo sentido que el original.

- Sinsentidos: segmentos del texto traducido que no serían comprendidos por el lector final.

- Aciertos: segmentos del тм en que la traducción es especialmente buena, ya sea porque propone una solución original, creativa $-\mathrm{y}$ adecuada al encargo, por supuesto- a alguno de los problemas que presenta el texto, $o$ porque la traducción suena como un texto original en LM, gracias a la cohesión y coherencia, etc.

Subcompetencias: estratégica, ya que los estudiantes revisan y evalúan el texto producido por otro grupo; interpersonal, pues deben identificar y clasificar los errores detectados, y fundamentar las decisiones tomadas ante el otro grupo, y comunicativa y textual, al tener que demostrar dominio de las lenguas fuente y meta para la revisión.

6 Estas categorías son una propuesta de Orozco (2000) en su tesis doctoral para el desarrollo de un instrumento de medida de errores de traducción. 
Tabla 10. Errores de traducción.

\begin{tabular}{|c|c|c|c|c|}
\hline Ejemplos & $\begin{array}{l}\text { Errores de } \\
\text { traducción } \\
\text { pragmáticos }\end{array}$ & $\begin{array}{l}\text { Errores de } \\
\text { traducción } \\
\text { culturales }\end{array}$ & $\begin{array}{l}\text { Errores de } \\
\text { traducción } \\
\text { lingüísticos }\end{array}$ & $\begin{array}{l}\text { Infracción de } \\
\text { normas en lengua } \\
\text { meta }\end{array}$ \\
\hline Incoherencia en el TM & Coherencia & & & \\
\hline Información incorrecta & Información & & & \\
\hline $\begin{array}{l}\text { Insuficiente explicación de } \\
\text { una realidad cultural de св }\end{array}$ & Destinatario & & & \\
\hline No adaptación de deícticos & $\begin{array}{l}\text { Lugar } \\
\text { Tiempo }\end{array}$ & & & \\
\hline $\begin{array}{l}\text { No obediencia a las } \\
\text { exigencias de formato }\end{array}$ & Medio & & & \\
\hline $\begin{array}{l}\text { Sistemas de medidas } \\
\text { inadecuado }\end{array}$ & & Medidas & & \\
\hline $\begin{array}{l}\text { Convenciones textuales } \\
\text { inadecuadas }\end{array}$ & & Género & & \\
\hline $\begin{array}{l}\text { No adaptación de } \\
\text { convenciones estilísticas }\end{array}$ & & Estilo & & \\
\hline $\begin{array}{l}\text { Interferencia léxica (falso } \\
\text { amigo) con LB }\end{array}$ & & & Léxico & \\
\hline $\begin{array}{l}\text { Malinterpretación de una } \\
\text { estructura sintáctica }\end{array}$ & & & Sintaxis & \\
\hline Focalización equivocada & & & Focalización & \\
\hline Declinación incorrecta & & & & Gramaticales \\
\hline Palabra mal formada & & & & Morfologías \\
\hline Fraseologismo incorrecto & & & & Sintácticas \\
\hline Orden de palabras incorrecto & & & & Sintácticas \\
\hline Falta de puntuación & & & & Puntuación \\
\hline Falta de ortografía & & & & Ortografía \\
\hline
\end{tabular}

\section{Tarea 19. Errores de traducción}

Objetivo de la tarea: evaluar, en la traducción de un par, los errores de traducción pragmáticos, culturales, lingüísticos y derivados de convenciones.

Instrucción: el docente solicita a los equipos de trabajo que evalúen la traducción realizada por otro grupo sobre la base de la matriz que se presenta a continuación. ${ }^{78}$ Luego, los estudiantes exponen su evaluación ante la clase.

Subcompetencias: comunicativa y textual y estratégica, ya que los estudiantes revisan y evalúan

7 Matriz para la evaluación de traducciones propuesta por Nord (2006, p. 39).

8 Para la evaluación de traducciones, también se pueden utilizar las matrices de La Rocca (2001), Williams (2004) o Colina (2008). 
Tabla 11. Problemas de lengua española.

\begin{tabular}{l|l|l|l}
\hline & Fragmento del texto & Norma del español & $\begin{array}{l}\text { Propuesta de } \\
\text { mejora }\end{array}$ \\
\hline Errores de lengua española & & & \\
\hline Tiempo verbal & & & \\
Concordancia de género & & & \\
$\ldots$ & & & \\
Errores ortotipográficos & & & \\
Mayúsculas & & & \\
\hline Comillas & & & \\
\hline Siglas & & & \\
\hline
\end{tabular}

el texto producido por otro grupo, e interpersonal, al acordar cuáles y de qué tipo son los errores identificados y presentar la evaluación realizada ante la clase.

\section{Tarea 20. Problemas de lengua española}

Objetivo de la tarea: identificar y solucionar problemas de lengua española presentes en el texto traducido por un par.

Instrucción: el docente solicita a los estudiantes que lean la traducción realizada por otro grupo sin tener a la vista el texto original. Luego, marcan las partes del texto que les parecen no se adecúan a las normas de la lengua española, las registran en una tabla indicando la clasificación del error (tiempo verbal, concordancia de número, etc.) y fundamentan el error a partir de la norma del correcto uso del español. Posteriormente, los estudiantes realizan el mismo ejercicio con los errores ortotipográficos (uso de mayúsculas, siglas y acrónimos, raya, guion, abreviaturas y unidades de medida, punto, puntos suspensivos, vocablos extranjeros, etc.).

Subcompetencias: comunicativa y textual y estratégica, pues los estudiantes revisan y evalúan el TM realizado por otro grupo; e interpersonal, ya que deben acordar cuáles y de qué tipo son los errores identificados y justificar las decisiones tomadas.

\section{El aprendizaje basado en proyectos}

En el entendido de que el ABP es una metodología de aprendizaje que permite que los estudiantes adquieran conocimientos y competencias cruciales para dar respuesta a un problema real y que, como dice el dicho popular "la realidad supera la ficción", resulta relevante que antes de enfrentar un proyecto, el docente tenga seguridad de que el estudiante cuenta con los recursos disciplinares y personales necesarios para dar respuesta a este problema y producir una traducción efectiva según el encargo (Nord, 1991). Esto no quiere decir que el estudiante lo debe saber todo, porque a veces nos enfrentamos a situaciones que nos presentan lo inimaginable, sino que debe estar dispuesto a aprender haciendo utilizando nuevas lógicas, nuevas combinaciones de estrategias, desarmando probablemente el tránsito lógico, hasta ahora más o menos estable, dentro del proceso traductor.

De acuerdo con Kiraly (2000) cambiar el foco de atención en las clases de traducción de la transmisión unidireccional de conocimientos del profesor al estudiante a una interacción multidireccional entre todos quienes participan en el proceso resulta necesario. Este cambio de paradigma conlleva una modificación en los roles dentro de aula, en el funcionamiento psicológico (el estudiante elabora, 
diseña, colabora) e incluso una modificación de la disposición en el espacio del aula - ya no estamos frente a frente como en una clase magistral, sino que nos movemos, nos relacionados, trabajamos en grupo.

En términos de Galán (2007), el ABP a diferencia del EPT tiene que desarrollar productos más complejos y generalmente reales. La complejidad en el caso de las tareas de traducción se puede relacionar, por ejemplo, con el distanciamiento entre la situación de enunciación del To y la del TM o el distanciamiento entre las lenguas de trabajo, así como también con la especialización del tema, la extensión del texto, el formato solicitado, el contacto con el cliente, entre otros aspectos.

En el tránsito del EPT al ABP se pueden trabajar las variables antes mencionadas con el fin de que el estudiante se prepare para enfrentar algunos posibles escenarios complejos. Por ejemplo, respecto de la situación de enunciación, de acuerdo con Nord (1991, 2009), la traducción en tanto interacción comunicativa se ve delimitada en cuanto al espacio y al tiempo, se da bajo determinados parámetros históricos y culturales que son los que guían la producción e interpretación del texto para traducir. Este contexto del To a TM puede cambiar y obliga a moldear la traducción de acuerdo con lo planteado en el encargo de traducción. La acción de moldear conlleva decisiones de parte de los traductores, como por ejemplo decidir si acercar la cultura del To a la cultura del TM o bien hacer uso de la extranjerización. Una actividad didáctica para dar cuenta de la complejidad respecto de la situación de enunciación es comparar libros o series traducidas en distintas épocas.

En relación a las lenguas de trabajo, el traductor requiere de un gran dominio de ambas lenguas y de sus implicaciones culturales, dado que cuando se trata de traducir estamos frente a un ejercicio tan lingüístico como cultural. Si bien toda traducción demanda de un conocimiento acabado de las diferencias culturales, esto resulta ser más evidente en la traducción publicitaria en la que en palabras de Valdés (2004, p. 70) la responsabilidad del traductor es "comunicar el mensaje básico de toda la campaña publicitaria a un receptor con una lengua, costumbres y valores diferentes, en definitiva, con unas normas distintas". De acuerdo con el autor, dado que el receptor es el que determina los objetivos como las funciones del texto, para trabajar la complejidad asociada a las lenguas de trabajo en un contexto de clases, se puede modificar el encargo de traducción respecto de estas dos variables. Por ejemplo, podemos promover la venta de un producto o bien solo darlo a conocer, podemos intentar bajar el producto de la competencia o bien solo informar respecto de sus características, etc.

Respecto de la especialización del tema, cabe mencionar que la traducción especializada requiere de un texto especializado escrito en lengua de especialidad que se enmarque en una situación comunicativa especializada dentro de un campo del saber determinado. Una de las grandes dificultades del discurso especializado es que se surte de lo que dispone cada lengua para dar vida a este discurso especializado y, por lo mismo, las unidades léxicas con las que cuenta son versátiles, en tanto pueden moldearse semánticamente a diferentes contextos de uso. Para trabajar este tema, el uso de distintos traductores automáticos es de gran utilidad. Se divide al curso en grupos, se les pide identificar fraseología y terminología del área del texto de trabajo, y luego se les indica con qué traductor automático trabajará cada grupo. Una vez realizada la traducción, las versiones pasan por el ojo humano, el que las analiza, compara y, finalmente, con la ayu- 
da de glosarios, diccionarios, textos paralelos, entre otros recursos que apoyan la tarea del traductor, prepara una versión mejorada. Con esta tarea se busca que el estudiante aplique mecanismos de revisión, los que tal como menciona Parra (2005) le permiten comparar el texto de llegada con el texto de origen y, a partir de este contraste, corregirlo y mejorarlo en función de las especificaciones del encargo de traducción. Dado que, en este caso, se pretende evidenciar la complejidad de la tarea de traducción en la especialización del tema, se espera que el estudiante realice una revisión, principalmente, a nivel idiomático evaluando que el uso de los términos sea el adecuado. Se utiliza el adverbio principalmente porque resulta complejo que se pueda efectuar la revisión solo a un nivel del texto en tanto los aspectos semánticos, estilísticos, culturales, entre otros, están interrelacionados y por lo tanto, también deben ser revisados, sobretodo, en este estadio de formación.

En relación a la complejidad de la tarea de traducción y la variable del contacto con el cliente, en ocasiones la relación con este no permite que el trabajo de pretraducción definido en esta investigación se lleve a cabo de forma lógica y fluida. Una actividad para dar cuenta de este escenario es trabajar con solicitudes de trabajo que dan cuenta de condiciones no óptimas para la ejecución del trabajo, como, por ejemplo, con solicitudes que restringen el tiempo para emitir la orden de trabajo, lo que implica a su vez, no poder realizar una lectura completa y exhaustiva de Tо y, por ende, no organizar cabalmente el trabajo en función del encargo de traducción. Delisle y Bastin (2006) afirman que "Cualquier texto incluye siempre cuatro elementos: el autor, el tema tratado, el medio (tipo de texto, recursos lingüísticos utilizados) y el destinatario" (p. 130). Frente a una situación estresante en términos de tiempo, resulta complejo barajar estos elementos para tener un pa- norama general pero claro de la situación antes de asumir un trabajo de traducción. Junto con esto y dado que en el contexto nacional chileno no se conoce claramente la labor que realiza el traductor, realizar juegos de roles resulta de gran relevancia para dar cuenta de situaciones reales que para el estudiante de traducción parecen impensables/ser inesperadas; en muchas ocasiones no está claro si el servicio que se requiere es una traducción o una interpretación, qué parte del documento se quiere traducir, a quién va dirigida la traducción, qué es un programa traductor, cómo es el sistema de cobro, entre otros aspectos.

Cualquiera de estos elementos que dan cuenta de la complejidad del encargo de traducción son variables a controlar mientras la metodología de trabajo en el aula sea el EPT y no el APB. En este último el estudiante recibe un texto acompañado de un encargo real de traducción al que debe responder con su grupo de trabajo, activando todas sus herramientas tanto disciplinares como personales, en donde el docente tiene un rol pasivo y solo acompaña el proceso en tanto todavía la situación de trabajo se da en el aula. El trabajar con material auténtico y en un proyecto real de traducción hace posible que el estudiante desarrolle la competencia traductora al asociar (y no disociar) la teoría de la práctica, al incorporar los contenidos adquiridos en otras asignaturas y ser capaz de construir su propio aprendizaje. En este escenario, las actividades antes mencionadas que contempla el proceso traductor el estudiante las enfrenta de manera autodirigida, ya no son lineales ni guiadas por el docente, la situación es la que indica el cómo transitar en este proceso traductor promoviendo así la responsabilidad, la autonomía y también la colaboración. 


\section{Conclusiones}

Este trabajo nace de una reflexión acerca de la integración del aprendizaje de diversas áreas y materias por parte del estudiante de traducción al momento de enfrentar un encargo de traducción. Esta (no) integración nos llevó a preguntarnos qué metodologías de trabajo en el aula, asociadas a qué subcompetencias de la competencia traductora, podrían ayudar a apoyar el proceso traductor con el fin de que los estudiantes logren mejores resultados. Como respuesta a esta interrogante, la aplicación de las actividades presentadas derivó en algunas reflexiones principalmente en el orden didáctico, aunque también se presentan algunas en el orden social.

En lo referente a lo didáctico, este trabajo nos permitió evaluar la pertinencia de las metodologías de EPT y ABP para el desarrollo de la competencia traductora y reflexionar acerca de las metodologías de enseñanza utilizadas, con el fin de desarrollar actividades integradas. La propuesta es identificar líneas de trabajo en el itinerario formativo, por ejemplo, los talleres de traducción en las áreas de las ciencias y tecnologías, y transitar por etapas y de forma progresiva de un EPT, en el que, si bien el estudiante igualmente tiene protagonismo en su aprendizaje (Marco, 2004), recibe instrucción explícita de parte del docente, a un ABP. En este tránsito, los estudiantes se van apropiando de algunas de las tareas y las van internalizando hasta llegar al punto de efectuarlas de manera automática; por ejemplo, aprenden a hacer una lectura rápida $\mathrm{y}$ focalizada del texto con el fin de extraer información importante para llenar una orden de trabajo y organizar las tareas, y no dedican tiempo a una lectura exhaustiva que si bien es muy útil para la comprensión cabal del texto, no les proporciona muchos más antecedentes para la toma de decisiones que la etapa de pre- traducción requiere; dependiendo del tema a traducir, ya cuentan con material de referencia clasificado y son capaces de evaluar, con solo mirar, la fiabilidad de los recursos documentales y terminológicos que ofrece la internet. Por su parte, los grupos de trabajo van adquiriendo la autonomía necesaria para planificar y tomar decisiones en función de los objetivos de la tarea, e incluso son capaces de reflexionar sobre el proceso que están llevando a cabo y orientar el trabajo que la traducción de un texto demanda. En el EPT, resulta relevante lograr que el estudiante evidencie la complejidad del proceso traductor con cada una de las tareas que debe realizar y que logre "sacar provecho" de cada una de estas para dar cumplimiento al objetivo final: dar respuesta a su encargo. Con "sacar provecho" nos referimos a hacer un uso efectivo e intencionado de algunos de los recursos que el estudiante tiene a su disposición - de ahí que le solicitamos leer el texto antes de completar la "orden de trabajo", dado que esta no solo sirve para dar cuenta del número de palabras a traducir y lo que se va a cobrar por ese trabajo, sino que además nos permite conocer más en detalle el tema, la complejidad del texto, los recursos de los que debemos disponer para enfrentar la tarea $\mathrm{y}$, con esto, estimar de manera más fiel el plazo de entrega-. La propuesta considera que, en cada uno de los niveles del currículo, cada una de las actividades que se diseñe finalice con un texto traducido, y que el objetivo de la tarea se vea reflejado en el marco teórico, en el tiempo de dedicación al contenido en cuestión y en el porcentaje de la evaluación de dicho contenido; consideramos fundamental que las actividades de aula se sitúen en la práctica real de la traducción.

En términos sociales, el trabajo en aula con el uso de ambas metodologías permite que el estudiante evidencie el proceso traductor y la complejidad que este reviste. Tal como se 
mencionó anteriormente, en el contexto nacional chileno, los programas de formación de pregrado actuales no exigen un estándar mínimo de manejo en la segunda o tercera lengua de trabajo, lo que, además de generar un distanciamiento importante entre la teoría y la práctica, genera una percepción por parte del estudiante que ingresa a traducción que el trabajo que debe realizar no tiene gran complejidad. La mirada más bien técnica, que da cuenta de que solo es necesario tener conocimientos lingüísticos para poder traducir, cambia al constatar las tareas que el proceso traductor conlleva, las que dan cuenta de que este profesional es un comunicador, y que como comunicador, según Álvarez (2004), requiere ser competente a nivel sociocultural, discursivo y lingüístico; cambia al constatar que la traducción no es un proceso mecánico que da cuenta de un producto correcto desde el punto de vista del sistema de la lengua sino que requiere prestar atención suficiente a aspectos discusivos o comunicativos, en tanto es un proceso cognitivo complejo.

Tal como indica Kelly (2005), la diferencia entre el ABP y el EPT radica en el momento de la enseñanza en el que se ubican. El estudiante durante su proceso de formación va adquiriendo conocimientos y desarrollando competencias tanto específicas como genéricas que le permiten enfrentar con éxito un encargo de traducción. En este entendido, en un nivel inicial es recomendable un trabajo más guiado, paso a paso, como el que se expone en la actividad didáctica presentada, el que se va liberando casi naturalmente en la medida en que el estudiante transita a un nivel más avanzado. En el nivel avanzado, encargos más complejos en los términos descritos, sumados a un trabajo en equipo, configurarían el escenario ideal para integrar todas las subcompetencias que supone la competencia traductora, en tanto el trabajo mancomunado conlleva aprender a coordinarse; mejorar la propia organización, así como también la exigencia con uno mismo (dado que el trabajo propio repercute en el de los demás integrantes del grupo); aprender a negociar, establecer criterios, debatir y justificar; y saber cómo respetar y considerar la opinión de otros. Como señala Muñoz (2015), trabajar estas subcompetencias de forma colaborativa posibilita que el aprendiz de traducción realice de forma competente su labor traductora y lo ayuda a perfilar su identidad profesional.

\section{Referencias}

Álvarez, G. (2004). Textos y discursos: introducción a la lingüistica del texto. Concepción: Universidad de Concepción, Facultad de Humanidades y Arte.

Atlas Copco. (2007). Mineral Prospecting and Exploration. En Mining Methods in Underground Mining (Segunda edición) (pp. 13-16). Örebron: Suecia. Recuperado de https://bit.ly/2zNF6N1.

Beeby, A. (1996). Teaching Translation from Spanish to English. Ottawa: University of Ottawa Press.

Bell, R. (1991). Translation and Translating: Theory and Practice. Londres: Longman.

Colina, S. (2008). Translation Quality Evaluation: Empirical Evidence for a Functionalist Approach. The translator, 14(1), 97-134. doi:10.1080/13556509.2008.107 99251

Delisle, J. (1980). L'analyse du discours comme méthode de traduction: Initiation à la traduction française de textes pragmatiques anglais, théorie et pratique. Ottawa: Presses de l'Université d'Ottawa.

Delisle, J. y Bastin, G. (2006). Iniciación a la traducción. Enfoque interpretativo. Teoría y Práctica. Colección estudios, Consejo de Desarrollo Científico y Humanístico. Caracas: Universidad Central de Venezuela. 
Escamilla, J. (1999). Selección y uso de tecnología educativa. México: Trillas

Etapas de la Minería - Prospección [Video] (2013, 10 de marzo). Recuperado de https://www. youtube.com/watch? $\mathrm{v}=\mathrm{s} 3 \mathrm{frp} 5 \mathrm{iNGo}$.

Fernández, S. (2010). Enfoque de acción: Aprender lenguas con "Tareas". En S. Fernández y A. Navarro (eds.), Enfoque por tareas. Propuestas didácticas. España: Secretaría General Técnica.

Galán, A. (2007). La enseñanza por competencias, por tareas y por objetivos de aprendizaje: el caso de la traducción jurídica portugués-español. Íkala, 12(18), 27-57.

Galeana, L. (2006). Aprendizaje basado en proyectos. CEUPROMED, 1(27). Recuperado de http://ceupromed.ucol.mx/revista/ PdfArt/1/27.pdf.

García Yebra, V. (1982). Teoría y práctica de la traducción. Madrid: Gredos.

Gile, D. (1995). Basic Concepts and Models for Interpreter and Translator Training. Ámsterdam: John Benjamins.

Hansen, G. (1997). Success in Translation. Perspectives: Studies in Translatology, 5(2), 201-210.

Hatim, B. y Mason, I. (1997). The Translator as Communicator. Londres: Routledge.

Hurtado, A. (1999). Objetivos de aprendizaje y metodología en la formación de traductores e intérpretes. En A. Hurtado (ed.), Enseñar a traducir (pp. 8-58). Madrid: Edelsa.

Hurtado, A. (1996). La cuestión del método traductor: método, estrategia y técnica de traducción. Sendebar, 7, 39-58.

Kelly, D. (2002). Un modelo de competencia traductora: bases para el diseño curricular. Puentes, 1, 9-20.

Kelly, D. (2005). A Handbook for Translator Trainers. Manchester, St. Jerome.

Kiraly, D. (1995). Pathways to Translation. Pedagogy and Process. Kent: Kent State University Press.
Kiraly, D. (2000). A Social Constructivist Approach to Translator Education. Empowerment from Theory to Practice. Manchester, Reino Unido: St. Jerome Publishing.

La Rocca, M. (2001). El taller de traducción: una metodología didáctica integradora para la enseñanza universitaria de la traducción [tesis doctoral]. Universitat de Vic, España. http://www.tdx.cat/TDx-0504107-095313

Lobato, J. (2013). Propuesta didáctica para las clases de traducción especializada: el aprendizaje basado en proyectos. Tonos Digital, (25). Recuperado de https://goo. gl/ZZLtha

Lowe, P. (1987). Revising the ACTFL/ETs Scales for a New Purpose: Rating Skill in Translating. En M. Gaddis Rose (Ed.), Translation Excellence: Assessment, Achievement, Maintenance (pp. 53-61). Nueva York: Binghamton Press.

Marco, J. (2004). ¿Tareas o proyectos? ¿Senderos que se bifurcan en el desarrollo de la competencia traductora? TRANS, (8), 75-88.

Miras, M. (2002). Un punto de partida para el aprendizaje de nuevos contenidos: Los conocimientos previos. En C. Coll, E. Martín, T. Mauri, M. Miras, J. Onrubia, I. Solé y A. Zabala (eds.), El constructivismo en el aula (pp. 47-64). Barcelona: Editorial Graó.

Muñoz, A. (2015). El desarrollo de la competencia traductora a través de la socialización con el experto en la materia: una experiencia didáctica. The Journal of Specialised Translation, (23), 333-351. Recuperado de https://goo.gl/YL2AVr

Neubert, A. (2000). Competence in Language, in Languages and in Translation. En J. Beverly y C. Schäffner (eds.), Developing Translation Competence (pp. 3-18). Ámsterdan-Filadelfia: John Benjamins.

Nord, C. (1991). Text Analysis in Translation. Theory, Method and Didactic Application of a 
Model for Translation Oriented Text Analysis. Ámsterdam/Atlanta GA: Rodopi.

Nord, C. (1992). Text Analysis in Translator Training. En C. Dollerup y A. Lindegaar (eds.), Teaching Translation and Interpreting 1 (pp. 39-48). Ámsterdam: John Benjamins.

Nord, C. (2006). El horizonte de expectativas en la evaluación funcional. En M. Varela (ed.), La evaluación en los estudio de traducción e interpretación (pp. 30-46). Sevilla: Bienza.

Nord, C. (2009). El funcionalismo en la enseñanza de la traducción. Mutatis Mutandis, 2(2), 209-243.

Orozco, M. (2000). Instrumentos de medida de la adquisición de la competencia traductora: Construcción y validación [tesis doctoral]. Universitat de Barcelona, España. https://www.tdx.cat/handle/10803/5272

Orozco, M. (2012). Metodología de la traducción directa del inglés al español. Materiales didácticos para la traducción general y especializada ( $2^{a}$ edición). Granada: Interlingua.

PACTE (2000). Acquiring Translation Competence: Hypotheses and Methodological Problems of a Research Project. En A. Beeby, D. Ensinger y M. Presas (eds.), Investigating Translation (pp. 99-106). Ámsterdam: John Benjamins.

PACTE (2003). Building a Translation Competence Model. En F. Alves (ed.), Triangulating Translation: Perspectives in Process Oriented Research (pp. 43-66). Ámsterdam: John Benjamins.

Parra, S. (2005). La revisión de traducciones en la Traductología: Aproximación a la práctica de la revisión en el ámbito profesional mediante el estudio de casos y propuestas de investigación [Tesis doctoral]. Universidad de Granada, España. Recuperado de https://bit. ly/2DpuJQF.
Presas, M. (1996). Problemes de traducció i competència traductora: bases per a una pedagogia de la traducció [tesis doctoral]. Universitat Autònoma de Barcelona, España. Recuperado de https://www.tdx.cat/handle/10803/5273.

Pym, A. (1992). Translation Error Analysis and the Interface with Language Teaching. En C. Dollerup y A. Loddegaard (eds.), Teaching Translation and Interpreting. Training, Talent, and Experience (pp. 279290). Amsterdam: John Benjamins.

Roberts, R. (1984). Compétence du nouveau diplômé en traduction. En Traduction et Qualité de Langue. Actes du Colloque Société des traducteurs du Québec/ Conseil de la langue française (pp. 172-184). Québec: Éditeur officiel du Québec.

Risku, Hanna (1998). Translatorische Kompetenz. Kognitive Grundlagen des Übersetzens als Expertentätigkeit. Tubinga: Stauffenburg.

Sánchez, G. (2012, 23 de agosto). Exploración y Minería Subterránea [Vídeo]. Recuperado de https://www.youtube.com/watch?$\mathrm{v}=\mathrm{nn} 4 \mathrm{U} 7 \mathrm{Gz} 6 \mathrm{fIw}$

Sevilla, M., Sevilla, J. y Callejas, V. (2003). Propuesta de una unidad didáctica de traducción científico-técnica dirigida a alumnos universitarios. Cadernos de Tradução, 12, 109-125. doi: 10.5007/\%25x

Shreve, G. M. y Koby G. S. (1997). What's in the 'Black Box'? Cognitive Science and Translation Studies. En H. J. Danks, G. M. Shreve, S. B. Fountain, y M. K. McBeath (eds), Cognitive Processing in Translation and Interpreting (pp. 11-18). Thousand Oaks: Sage.

Thomas, J. (2000). A Review of Research on Project-based Learning. Recuperado de https:// bit.ly/2K9egFE

Valdés, C. (2004) La traducción publicitaria: comunicación y cultura. Universidad Autónoma de Barcelona. Barcelona: Servei de Publicacions UAB. 
Valero, M. y Navarro, J. (2008). La planificación del trabajo del estudiante y el desarrollo de su autonomía en el aprendizaje basado en proyectos. En J. García-Sevilla (ed.), El aprendizaje basado en problemas en la enseñanza universitaria (cap. 9). Servicio de Publicaciones de la Universidad de Murcia. Recuperado de https://bit. ly/2AVg7aF.

Weinberg, J., Caamaño, R. y Mondaca, L. (2018). Comprensión lectora: propuestas didácticas para el lector-traductor. Sendebar, (29), 305-327. doi: 10.30827/sendebar.v29i0.6475
Williams, M. (2004). Translation Quality Assessment: an Argumentation-Centred Approach. Ottawa: University of Ottawa Press.

Wilss, W. (1976). Perspectives and Limitations of a Didactic Framework for the Teaching of Translation. En R. Brislin (ed.), Translation Applications and Research. Richard (pp. 117-137). Nueva York: Gardner.

Cómo citar este artículo: Weinberg Alarcón, J. y Mondaca Becerra, L. (2019). ¿Cómo transitar en el aula para adquirir la competencia traductora? Del aprendizaje por tareas al aprendizaje basado en proyectos. Mutatis Mutandis. Revista Latinoamericana de Traducción, 12(1), 126-155. DoI: https://doi.org/10.17533/ udea.mut.v12n1a05 